\title{
Bilecik Bahçelievler Neolitik Çağ Yontmataş Topluluğuna Ait I̊lk Değerlendirmeler
}

\section{Preliminary Evaluations of the Bilecik Bahçelievler Neolithic Chipped Stone Assemblage}

\author{
Neyir Kolankaya-Bostanc1 ${ }^{1} @$, Erkan Fidan ${ }^{2} \Subset$
}

'Hacettepe Üniversitesi, Edebiyat Fakültesi, Arkeoloji Bölümü, Ankara, Türkiye

2 Şeyh Edebali Üniversitesi, Fen-Edebiyat Fakültesi, Arkeoloji Bölümü, Bilecik, Türkiye

ORCID ID: N.K.B. 0000-0002-3798-9444; E.F. $0000-0002-6777-927 X$

Sorumlu yazar/Corresponding author: Neyir Kolankaya-Bostancı (Doç. Dr.), Hacettepe Üniversitesi, Edebiyat Fakültesi, Arkeoloji Bölümü, Ankara, Türkiye E-posta: neyirada@gmail.com

Başvuru/Submitted: 09.05.2021 Kabul/Accepted: 06.08 .2021

Atıf/Citation: Kolankaya-Bostanci, N., \& Fidan, E. (2021). Bilecik Bahçelievler neolitik çağ yontmataş topluluğuna ait ilk değerlendirmeler. Anadolu Araştırmaları-Anatolian Research, 24, 93-116.

https://doi.org/10.26650/anar.2021.24.935202

\section{ÖZ}

Bu makale, Bilecik Arkeoloji Müzesi başkanlığında sürdürülen Bahçelievler yerleşmesinde 2019 ve 2020 yılı kazı sezonları sırasında ele geçen yontmataş buluntulara dair ilk gözlemleri içermektedir. Kuzeybatı Anadolu'nun en eski yerleşmelerinden biri olan ve MÖ 7. binyılda yerleşim görmüş olan Bahçelievler yerleşmesindeki yontmataş buluntu grubu üzerine yapılan ilk değerlendirmeler, yerleşmede büyük oranda yerel çakmaktaşının kullanıldığını, bunun yanı sıra Orta Anadolu'dan ithal edilen obsidyenlerin de var olduğu bir yontmataş topluluğunu işaret etmektedir. Yongalama işleminin büyük oranda avlularda gerçekleşmiş olduğu Bahçelievler'de yontmataş topluluğu, dilgi ve dilgicik üretimine dayanmaktadır. Daha çok yapıların içinden ele geçen alet tipleri arasında yerleşimde tarımın önemli bir yer tuttuğunu gösteren orak dilgi ve dilgiciklerinin yoğunlukta olduğu görülmektedir. Bahçelievler Neolitik Çağ yontmataş topluluğu üzerine yapılan bu ilk çalışma, mermi biçimli çekirdekler ile keski ağızlı ok uçlarının varlığı ve baskı tekniği kullanımını ortaya koymasından dolayı, yerleşimde Kuzeybatı Anadolu'da özellikle de Menteşe ve Barcın Höyük'te yaşayan toplumların MÖ 7. Binyılda benzer teknolojileri kullanıldığını göstermiştir.

Anahtar Kelimeler: Kuzeybatı Anadolu, Bilecik, Bahçelievler, Neolitik, Yontmataş

\section{ABSTRACT}

This paper details the preliminary results of the chipped stone artifacts from the Bahçelievler settlement, uncovered during the 2019 and 2020 excavation seasons, which were directed by the Bilecik Archaeology Museum. The first evaluations of the lithic assemblage from Bahçelievler, one of the earliest sites in Northwest Anatolia, which was settled during the 7th millennium BC, show that local flint was used in the settlement to a greater extent than obsidian that was imported from Central Anatolia. At Bahçelievler, where the knapping was mostly carried out in courtyards, the lithic chipped stone assemblage is based on the production of blades and bladelets. Among the main tool types recovered from the buildings, sickle blades and bladelets are common, which indicates that agriculture had an important place in the life and economy of the settlement. This preliminary study of the Bahçelievler Neolithic chipped stone assemblage reveals the presence of bulletshaped cores and transverse arrowheads and the use of a pressure technique, suggesting that the communities living in Northwest Anatolia, especially Menteşe and Barcın Höyük, used similar technologies in the 7th Millennium BC.

Keywords: Northwest Anatolia, Bilecik, Bahçelievler, Neolithic, Chipped Stone 


\section{EXTENDED ABSTRACT}

As a result of the excavations carried out in 2019 and 2020 at Bahçelievler, a settlement located within the borders of the Bilecik province and dating back to the 7 th millennium $\mathrm{BC}$, a total of 435 chipped stone artifacts were found. This paper presents the first results of the techno-typological analysis of the Neolithic chipped stone artifacts, documented across the seven building levels of the settlement. Further, comparisons are made with the chipped stone assemblages excavated from the contemporary sites in the region.

The preliminary studies of the Bahçelievler Neolithic chipped stone artifacts show the use of two types of raw materials, local and imported. It is noteworthy that besides the dominant flint, which makes up $91 \%$ of the assemblage, obsidian finds are present at $9 \%$. Although no analysis of the sources has been carried out on obsidian samples, the macroscopic studies suggest that obsidian might be obtained from the Göllüdağ and Nenezidağ deposits in Central Anatolia. According to preliminary observations, the Bahçelievler Neolithic inhabitants seem to have used Nenezidağ obsidian more frequently than Göllüdağ obsidian. However, obsidian origin analyses are necessary to examine this issue in detail.

Knapping of flint, which was obtained from local sources, was carried out in the settlement, especially in courtyards. The scarcity of debris related to obsidian demonstrates that this raw material was mostly brought in as end products.

In the Bahçelievler lithic assemblage, there are bullet-shaped cores, end scrapers, borers, and transverse arrowheads, which are the characteristic artifacts of the Northwestern Anatolian Neolithic chipped stone industry. A flint bullet-shaped core, which comes from the lowest settlement layer of the Bahçelievler, dating 7000-6700 BC, represents one of the oldest bullet-shaped core examples obtained from the dated cultural layer in the region. The presence of bullet-shaped cores and transverse arrowheads at Bahçelievler and the use of a pressure technique reveal that the communities living in Northwest Anatolia had similar technical skills and shared similar techniques in chipped stone production in the 7 th millennium BC.

The Bahçelievler Neolithic chipped stone assemblage is generally based on the production of blades and bladelets. Bladelets make up the majority in the blanks group, followed by blades. There are some differences in the use of raw materials; for example, while obsidian was used for the production of bladelets, more bladelets and blades were produced from flint. The most likely reason for this may concern the use of obsidian, being an imported material, more economically.

Sickle elements make up the majority of tools in the lithic assemblage of the site. Bearing in mind that these tools were most likely used in harvesting, their abundance indicates that 
agriculture played an important role during the Neolithic period at Bahçelievler. In the tool assemblage, sickle elements are followed by end scrapers, arrowheads, borers, notched tools, and a single burin and a knife. Notably, blades were mostly used in the production of these tools. Finally, the Bahçelievler chipped stone tool assemblage is generally included in the northwestern Anatolian Neolithic lithic tool tradition with sickle elements, end scrapers, borers, and transverse arrowheads. This preliminary study of the Bahçelievler Neolithic lithic assemblage reveals that the general character of the settlement has great similarities with Northwest Anatolian sites, especially Menteşe and Barcın Höyük. The predominant use of local raw materials, the use of conical and bullet-shaped cores in blade and bladelet production, and the production of transverse arrowheads, borers, and end scrapers constitute strong evidence supporting this view. The extent $\mathrm{f}$ these similarities between the chipped stone assemblages of the contemporary settlements in the same region can be better understood after examining the other material groups. 


\section{Giriş}

Bu makaleyle 2019 ve 2020 yılı kazılarında ele geçen yontmataş buluntular üzerine yapılan ilk çalışmalar sunulmaktadır. Bahçelievler Neolitik Çağ tabakalarında gerçekleştirilen kazılar sonucunda toplam 435 adet yontmataş buluntu ele geçmiştir. Bu çalışmada Bahçelievler Neolitik Çağ yontmataş buluntularının tekno-tipolojik incelemelerinin ilk sonuçları verilecek ve ayrıca bölgedeki çağdaş buluntu yerlerindeki yontmataş toplulukları ile karşılaştırmaları yapilacaktır.

2013 yılında Prof. Dr. Turan Efe'nin Bilecik ilinde yürüttüğü yüzey araştırmaları kapsamında bulunan, günümüzde kurumuş bir su kaynağının hemen kenarına kurulduğu anlaşılan ve şehir merkezinde kalan Bahçelievler yerleşimi, inşaat faaliyetleri ve apartmanlar tarafından büyük oranda tahrip edilmiştir (Harita 1 ve Resim 1). Çevrede boş halde bulunan birkaç parselde 2019 yılından bu yana Bilecik Müze Müdürlüğü başkanlığında kurtarma kazıları sürdürülmektedir (Efe, vd. 2015; Fidan, 2020).

Yapılan kazılar, MÖ 7000'lerde bu alanda yerleşimin başladığını göstermektedir. Bu şekliyle Bahçelievler yerleşmesi bölgedeki Öncül Neolitik unsurları içermesi bakımından önemlidir. Kazılarda ilk evrelerden itibaren yuvarlak/oval planlı yapıların dal örgü tekniğiyle inşa edildiği, avluların ise işlik olarak kullanıldığı anlaşılmaktadır.

\section{Kronoloji}

Yerleşmede mimariye göre belirlenen sekiz yapı katının yedi tanesi prehistorik döneme aittir. Yapılan ${ }^{14} \mathrm{C}$ analizlerine göre bazı tabakalar mutlak olarak da tarihlendirilmiştir (Tablo 1). En eski tabaka olan 8. tabaka MÖ 7000-6700, 7. tabaka MÖ 6800-6600 ve 6. tabaka ise MÖ 6600-6500 yılları arasına denk gelmektedir ${ }^{1}$. Henüz mutlak tarihlemesi olmayan 5 ila 2. tabakalar ise MÖ 6500 sonrasına tarihlendirilmektedir. Yerleşmede çanak çömlek verilerinin ilk değerlendirmesine göre Fikirtepe Kültür öğelerinin 6. tabakada görülmeye başladığı, 5 . tabakada baskın hale gelen bu öğelerin 4 ve 3. tabakalarda da devam ettiği anlaşılmıştır. Diğer tabakaların aksine 2. tabakada ise yuvarlak evlerin yerini dörtgen evler alır ve malzemede de bazı değişimler görülür. Mutlak tarihlemesi henüz olmayan bu tabakalar MÖ 6500-5900 arasına tarihlendirilebilir. Bu şekliyle yerleşmede Çanak Çömlekli Neolitik'in yaklaşık 1000 yillık bütün süreci takip edilebilmektedir. En geç prehistorik tabaka Son Neolitik / İlk Kalkolitik olarak tanımlanabilir. En üstteki 1. tabaka ise Demir Çă̆ı'na aittir.

1 Analiz sonuçları için bkz Fidan 2020. Ayrıca henüz yayınlanmamış olan ve 6. tabakada ele geçirilen bir insan iskeletinin kaburga kemiğinden yapılan yaş tayini analizi, kalibre edilmiş tarihlere göre MÖ 6612-6471 aralı̆̆ını vermektedir. 


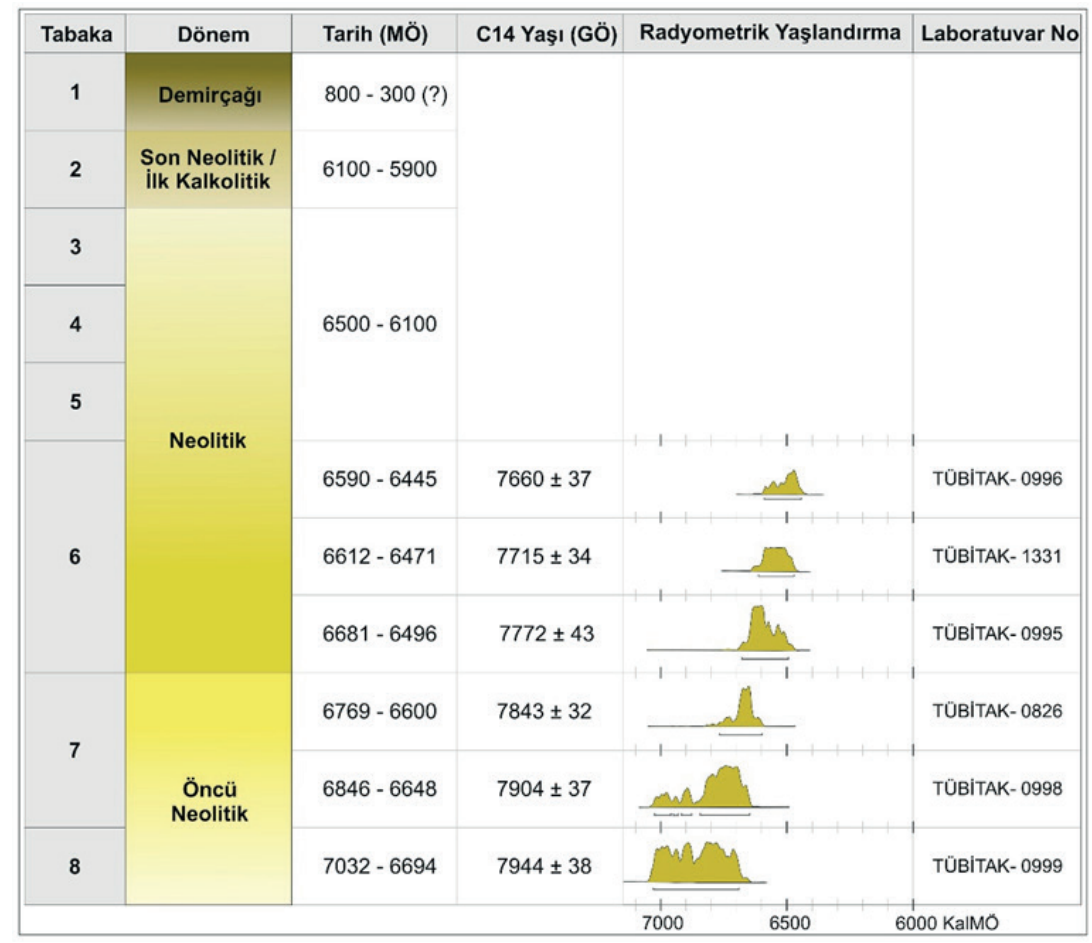

Tablo 1. Bahçelievler Yerleşmesi Kronoloji Tablosu

\section{Yontmataş Topluluğu}

Hammadde: Bahçelievler Neolitik Çağ yontmataş topluluğunda çakmaktaşı ve obsidiyenin kullanılmış olduğu görülmektedir. Buluntu topluluğunda çakmaktaşlarının hâkim olduğu dikkati çekmektedir (\% 91). Neolitik Çağ tabakalarından toplam 41 tane de obsidiyen buluntu ele geçmiştir (\% 9).

Çakmaktaşı topluluğu içinde üretimin yerleşim yerinde yapılmış olduğunu gösteren yongalama ürünlerine rastlanılmaktadır (Tablo 2 ve Grafik 1). Bunların büyük bir kısmının üzerinde kabuk kalıntısının bulunması, üretim artıklarının oldukça büyük boyutta olması ve benzer renk ve yapıda örneklerin bulunması, çakmaktaşı yatak ya da yataklarının yerleşimin yakınında olabileceğini göstermektedir. 


\begin{tabular}{|l|c|c|c|c|c|c|}
\hline Tabaka & Çekirdek & $\begin{array}{c}\text { Çekirdek } \\
\text { Hazırlama }\end{array}$ & $\begin{array}{c}\text { Üretim } \\
\text { Artıkları }\end{array}$ & Taşımalıklar & Aletler & TOPLAM \\
\hline 8 & 2 & 2 & 19 & 29 & 1 & 53 \\
\hline $7 \mathrm{c}$ & - & - & 3 & 4 & 3 & 10 \\
\hline $7 \mathrm{~b}$ & 1 & - & - & - & - & 1 \\
\hline $7 \mathrm{a}$ & - & - & - & 3 & - & 3 \\
\hline 6 & - & 1 & 34 & 19 & 1 & 55 \\
\hline 5 & - & 5 & 105 & 55 & 11 & 176 \\
\hline $4 \mathrm{~b}$ & - & - & 19 & 10 & - & 29 \\
\hline $4 \mathrm{a}$ & - & 2 & 23 & 24 & 3 & 52 \\
\hline 3 & - & - & 27 & 12 & 1 & 40 \\
\hline 2 & 1 & 2 & 9 & 3 & 1 & 16 \\
\hline TOPLAM & 4 & 12 & 239 & 159 & 21 & 435 \\
\hline
\end{tabular}

Tablo 2. Yongalama Ürünleri

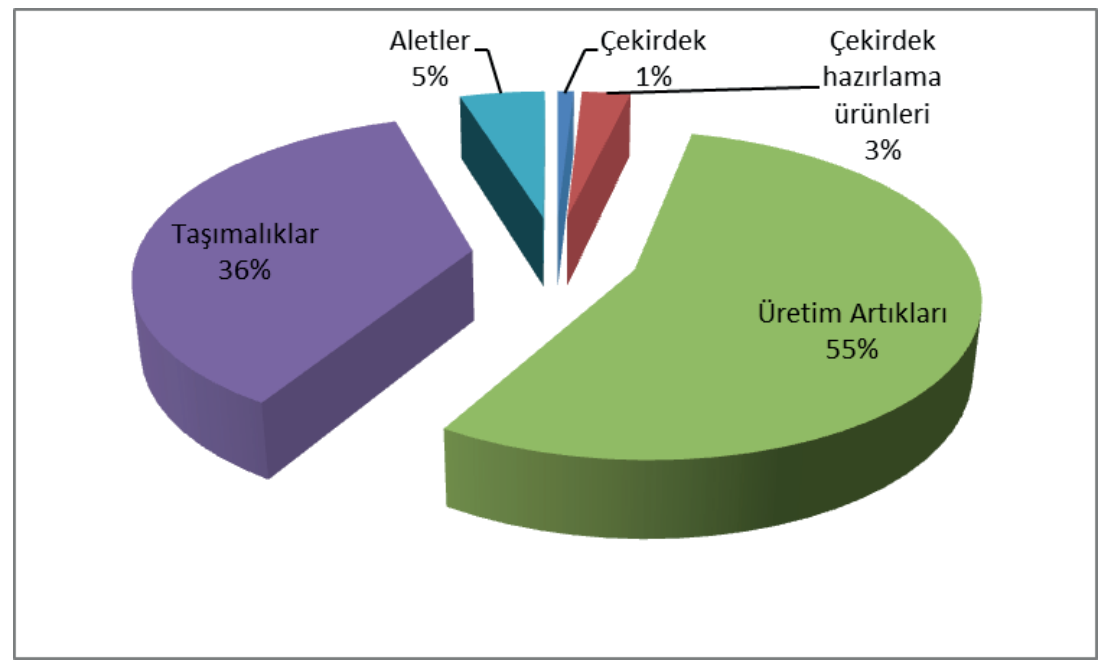

Grafik 1. Yongalama Ürünlerinin Oranları

Neolitik Çağ tabakalarının geneline bakıldığında çakmaktaşı yongalamanın daha çok avlularda gerçekleşmiş olduğu dikkat çekmektedir. Yerleşimin en alt tabakası olan 8. tabakada B2-18 olarak numaralandırılan avludan kabuklu büyük boydaki üretim artıklarının yanı sıra, 1 tanesi konik, diğeri ise mermi biçimli olmak üzere iki adet çekirdek, iki adet dönümlü dilgi parçası ve yanlış yongalanmış kabuklu bir yonga bulunmuştur. Söz konusu buluntular çakmaktaşı yongalamanın avluda gerçekleşmiş olduğunu düşündürmektedir.

Çakmaktaşı yongalama her ne kadar avlularda görülse de az da olsa ev içinde yapılan üretime dair izler de tespit edilmiştir. 5. tabakada açığa çıkarılan B3-19 olarak numaralandırılan 
ev içinde, yerleşimdeki diğer evlere oranla daha fazla miktarda çakmaktaşı ve obsidiyen buluntuya rastlanılmıştır (Resim 2). Bu ev içinde üretim artıklarının oldukça fazla olması, ayrıca yongalamanın yerleşimde yapıldığını gösteren çakmaktaşı ve obsidiyenden dönümlü dilgi ve dilgiciklerin bulunması, söz konusu evde hem çakmaktaşı hem de obsidiyen yongalamanın yapıldığını düşündürtmektedir.

İthal hammadde olan obsidiyen örnekler üzerinde herhangi bir kaynak yeri analizi henüz yapılmamış olsa da bunların morfolojik özelliklerine bakıldığında Göllüdağ ve Nenezi kökenli olduğu söylenebilir. Obsidiyen buluntuların makroskobik renk ve yapısına göre saydam ve yarı saydam mavimsi siyah renkte olan örneklerin Göllüdağ-Kayırlı kökenli olduğu düşünülmektedir. Diğer taraftan Bahçelievler obsidiyen buluntular arasında yer alan yeşilimsi gri renkte, genellikle opak ya da yarı opak olan ve dumanlı çizgili bir yapıya sahip olan örnekler ise Nenezi obsidiyeni olarak gruplanmaktadır (Kayacan ve Altınbilek-Algül, 2018, s. 367, Fig.2). Bu kriterlere dayanarak Bahçelievler'deki obsidiyen buluntuların büyük bir kısmının saydam ve yarı saydam olmasından ve renklerinin de mavimsi siyah renkte olup dumanlı çizgili bir yapıya sahip olmasından dolayı Nenezi obsidiyeninden daha fazla yararlanılmış olduğu düşünülmektedir. Nenezi obsidiyeninin daha fazla kullanılmış olması bu dönemde Orta Anadolu'daki çağdaş yerleşimlerde de görülen bir durumdur. Çatalhöyük'te yapılan çalışmalar, MÖ 7. binyılın başlarında obsidiyen kaynaklarının kullanımında bir değişikliğin olduğunu ve daha önce ağırlıklı olarak kullanılan Göllüdağ obsidiyeninin yerini Nenezi obsidiyenine bırakmış olduğunu ortaya koymaktadır (Carter ve Shackley, 2007, s. 443; Carter ve Milić, 2013, s. 496, 500). Bununla birlikte Orta Anadolu'da Nenezi obsidiyeninin kullanımı baskılama tekniğinin kullanılmaya başlanması ile aynı döneme, bir başka deyişle yaklaşık olarak MÖ 6500'lere denk gelmektedir (Conolly, 1999; Carter vd. 2006). Olasılıkla bölgeye gelen yeni gruplar ile birlikte yontmataş alet üretiminde kullanılan tekniklerde olduğu gibi, obsidiyen kaynak seçiminde de değişiklikler yaşanmıştır. Bu durum tüm Orta Anadolu Neolitik Çağ yerleşimlerini etkilediği gibi, görüldüğü kadarıyla Kuzeybatı Anadolu'da yer alan çağdaş yerleşimleri de etkilemiş olmalıdır.

Bahçelievler'de 2019 ve 2020 yılı kazı sonuçları değerlendirildiğinde her tabakada obsidiyen buluntuya rastlanmadığı dikkat çekmektedir (Tablo 3). Söz konusu tabakalar arasında Fikirtepe kültür öğelerinin de yaygınlaştığı 5 . tabakada obsidiyen buluntuların diğer tabakalara oranla daha fazla olduğu gözlemlenmiştir. 5. tabakadan toplam 19 tane obsidiyen taşımalık ele geçmiştir. Bu buluntuların büyük bir kısmını da dilgicikler oluşturmaktadır. Bahçelievler yerleşmesinde obsidiyen buluntular, çakmaktaşı buluntuların aksine evlerin içinden elde edilmiştir. Çekirdeklerin bulunmaması, çekirdek hazırlama ürünü olan dönümlü dilgicik ve üretim artıklarının ise oldukça az sayıda olmasından dolayı, obsidiyenin Orta Anadolu'dan tamamlanmış ürün olarak getirilmiş olma ihtimalini ortaya koymaktadır. 


\begin{tabular}{llllll}
\hline Tabaka & $\begin{array}{l}\text { Dönümlü } \\
\text { Dilgicik }\end{array}$ & $\begin{array}{l}\text { Üretim } \\
\text { Artığ } \mathbf{l}\end{array}$ & Dilgi & Dilgicik & TOPLAM \\
\hline $\mathbf{8}$ & - & - & - & 2 & 2 \\
\hline $\mathbf{7 c}$ & - & - & - & - & - \\
$\mathbf{7 b}$ & - & - & - & - & - \\
$\mathbf{7 a}$ & - & - & - & - & - \\
$\mathbf{6}$ & - & - & - & - & - \\
$\mathbf{5}$ & 2 & 1 & 1 & 15 & 19 \\
$\mathbf{4 b}$ & - & - & - & 5 & 5 \\
$\mathbf{4 a}$ & 1 & - & - & 7 & 8 \\
$\mathbf{3}$ & - & 2 & - & 2 & 4 \\
$\mathbf{2}$ & - & 1 & - & 2 & 3 \\
TOPLAM & 3 & 4 & 1 & 33 & 41 \\
\hline
\end{tabular}

Tablo 3. Obsidiyen Buluntuların Tabakalara Göre Dağılımı

Teknolojik ve Tipolojik Analizler: Çakmaktaşı yongalamanın yerleşim yerinde yapılmış olduğunu gösteren toplam 4 adet çekirdek ele geçmiş olup çekirdekler içinde bölgenin Neolitik Çağ' 1 için karakteristik olan tükenene kadar yontulmuş olan mermi biçimli çekirdeklerin varlığ 1 dikket çekicidir. Çekirdeklerin 3 tanesi mermi biçimli ve bir tanesi de konik biçimli çekirdek şeklindedir (Resim 3). Söz konusu çekirdekler Kuzeybatı Anadolu'da yer alan çağdaş buluntu yerlerinden, özellikle de Ilıpınar'dan ele geçen mermi biçimli çekirdekler ile yakın benzerlik göstermektedir (Gatsov, 2009, s. 117, Fig. 64: no: 4-6).

Bahçelievler'deki yerleşimin en alt tabakası olan 8. tabakadan hem mermi biçimli hem de konik biçimli çekirdek bir arada aynı avludan ele geçmiştir. Sözü edilen çakmaktaşı konik çekirdeğin tamamı korunmuş olup yüksekliği 3,94 cm ve genişliği de 3,03 cm'dir.

Çekirdek redüksiyonunda doğrudan ve dolaylı vurma ile baskılama teknikleri kullanılmıştır. Doğrudan vurma tekniğinden daha çok çekirdeğin ilk hazırlanması sırasında yararlanılmıştır. Bu teknikle çıkarılmış olan birçok iri boyutlu, vurma yumrusu oldukça büyük olan birçok kabuklu yongaya rastlanmıştır. Söz konusu örnekler yongalamanın ilk aşamaları ile ilgili olan yongalar olup daha sonra alet haline dönüştürülmemiştir. Dolaylı vurma tekniği ise çakmaktaşı ve obsidiyen dilgi ve dilgicik üretiminde kullanılmıştır. Baskı tekniğinden de hem çakmaktaşı hem de obsidiyen dilgicik çıkarımında yararlanılmıştır. Söz konusu paralel kenarlı taşımalıkların trapez kesitli, nokta topuklu oldukları ve vurma yumrularının da belirsiz olduğu görülmektedir. Bu teknik konik biçimli çekirdeklere uygulanmış olup söz konusu çekirdeklerin tükenene kadar yontulmalarını mümkün kılmıştır. Baskı tekniği ile yapılan yontmanın son aşamasında konik biçimli çekirdekler mermi biçimli çekirdekler haline dönüşmüştür. 
Çakmaktaşı mermi biçimli çekirdeklerin yükseklikleri $2,83 \mathrm{~cm} ; 3,14 \mathrm{~cm}$ ve 4,87 cm'dir (Resim 3). Söz konusu çekirdeklerin genişlikleri ise $0,63 \mathrm{~cm} ; 0,57$ ve 2,07 cm'dir. Çakmaktaşından yapılmış olan 3 tane mermi biçimli çekirdeklerden birinin en alttaki 8 . tabakada avlu içinden ele geçmiş olması, yerleşimde en eski tabakasından itibaren mermi biçimli çekirdeklerin kullanılmış olduğunu göstermektedir. Diğer iki mermi biçimli çekirdek ise $7 \mathrm{~b}$ ve 2. tabakada bulunmuştur. Bu durum, Bahçelievler Neolitik Çağ sakinlerinin bu dönemde Kuzeybatı Anadolu'da (Balc1, 2011) yaygın bir şekilde görünen mermi biçimli çekirdek geleneğini (Gatsov, 2009, s. 11) kullandığını ortaya koyar. Diğer taraftan, Bahçelievler'de MÖ 7000-6700 yılları arasına tarihlenen ve en alt tabaka olan 8. tabakada bulunan çakmaktaşından mermi biçimli çekirdek, en eski örneklerden birini oluşturmaktadır. Bahçelievler çakmaktaşı mermi biçimli çekirdeklerinin yakın benzerleri Aktopraklık (Balcı, 2011, Fig. 2-3) ve Barcın Höyük’te (Gatsov ve Nedelcheva, 2018) saptanmıştır. Barcın Höyük ve Aktopraklık’ta bu çekirdeklerden ayrıca kolye tanesi yapımında da yararlanılmış olduğu dikkat çeker (Gatsov ve Nedelcheva, 2018). Barcın Höyük’te kolye tanesi olarak kullanılmış olan çekirdekler obsidiyenden, Aktopraklık'ta ise çakmaktaşından yapılmıştır (Gatsov ve Nedelceva 2018, s. 302, Fig. 1). Batı Anadolu bölgesinde MÖ 7. binyılın ortalarından itibaren kullanılan bu çekirdek tipinin MÖ 6. binyılın ortalarına kadar yaklaşık 1000 yıl boyunca kullanılmış olması bölgesel bir gelenek olarak kabul edilebilir (Gatsov ve Nedelcheva, 2011, s. 93).

Taşımalık grubu içinde dilgiciklerin çoğunlukta olduğu ve bunları dilgilerin takip ettiği görülmektedir (Grafik 2). Söz konusu taşımalıkların üzertiminde dolaylı vurma tekniğinin kullanılmış olduğu görülmektedir. $\mathrm{Bu}$ durumda, Bahçelievler yontmataş topluluğunun aslında küçük boyutlu buluntulardan meydana geldiğini söylemek yanlış olmayacaktır.

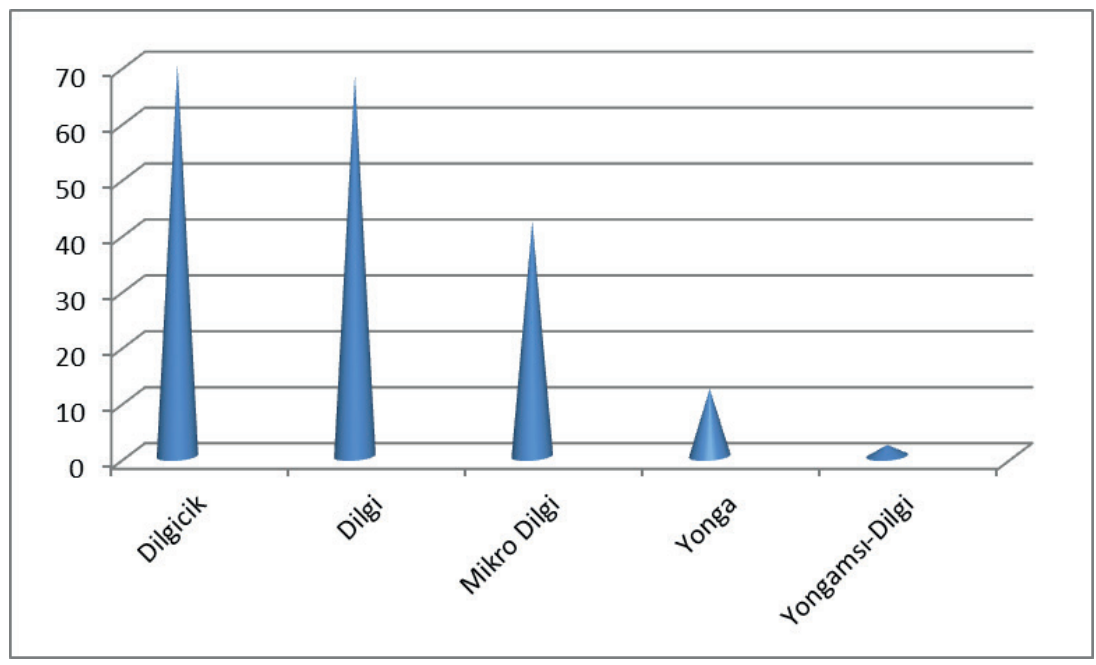

Grafik 2. Taşımalık Miktarı 
Hammadde kullanımına göre bazı farklılıklar dikkat çekmektedir, örneğin obsidiyenden dilgicik üretiminde yararlanılmışken, çakmaktaşından daha çok dilgicik ve dilgi üretimi yapılmıştır. Bunun en olası nedeni, obsidiyenin ithal malzeme olmasından dolayı daha ekonomik biçimde kullanılma kaygısı olabilir. Aynı durum Barcın Höyük’te de tespit edilmiştir (Gatsov vd. 2012, s. 129).

Bahçelievler Neolitik Çağ sakinlerinin yonga üretimini çok fazla yapmamış oldukları dikkat çekmektedir. Hâlbuki Kuzeybatı Anadolu'daki çağdaş buluntu yerlerine bakıldığı zaman söz konusu buluntu topluluklarında yonga üretiminin çok fazla yapmamış olduğu gözlemlenmektedir (Gatsov, 2003; Balc1, 2011, s. 3, Table 1). Ancak, Menteşe (Gatsov, 2003, s. 155) ve Barcin'da (Gatsov, 2009; Geritsen, 2010, s. 414; Gatsov vd.2012, s.130) ayn1 Bahçelievler'de olduğu gibi çakmaktaşı dilgi üretiminin yonga üretimine oranla daha fazla olduğu görülmektedir. Ayrıca az miktarda bulunan çekirdeklerin de hem dilgi hem de dilgicik üretiminde kullanılmış olması hem Menteşe (Gatsov, 2003, s.155) ve Barcın (Gatsov, 2009; Geritsen, 2010, s. 414) hem de Bahçelievler yontmataş topluluğunda görülen ortak bir özelliktir.

Yontmataş Aletler: Aletler arasında ise orak elemanlarının (10) çoğunlukta olduğu gözlemlenmektedir. Bunları sırasıyla ön kazıyıcılar (3), uçlar (2), delgiler (2), çentikli aletler (2), taş kalem (1) ve bıçak (1) takip eder. Yerleşimdeki tabakalar arasında en fazla yontmataş alet 5. tabakada tespit edilmiştir (Tablo 4).

\begin{tabular}{|c|c|c|c|c|c|c|c|c|}
\hline Tabaka & $\begin{array}{c}\text { Orak } \\
\text { Elemanı }\end{array}$ & Uçlar & $\begin{array}{c}\text { Ön } \\
\text { Kazıyıcı }\end{array}$ & Delgiler & $\begin{array}{l}\text { Çentikli } \\
\text { Aletler }\end{array}$ & $\begin{array}{c}\text { Taş } \\
\text { Kalem }\end{array}$ & Bıçak & TOPLAM \\
\hline 8 & 1 (Avlu) & - & - & - & - & - & - & 1 \\
\hline $7 c$ & $1(\mathrm{Ev})$ & - & - & - & - & - & - & 1 \\
\hline $7 b$ & $1(\mathrm{Ev})$ & - & - & $1(\mathrm{Ev})$ & 1 (Ev) & - & - & 3 \\
\hline $7 a$ & - & - & - & - & - & - & - & - \\
\hline 6 & $1(\mathrm{Ev})$ & - & - & - & - & - & - & 1 \\
\hline 5 & $\begin{array}{c}3(1 \mathrm{Ev} \\
\text { ve } 2 \\
\text { Avlu) }\end{array}$ & $\begin{array}{c}1 \\
\text { (Avlu) }\end{array}$ & 3 (Avlu) & - & $1(\mathrm{Ev})$ & $1(\mathrm{Ev})$ & - & 9 \\
\hline $4 b$ & 1 (Avlu) & - & - & - & - & - & - & 1 \\
\hline $4 a$ & $1(\mathrm{Ev})$ & $1(\mathrm{Ev})$ & - & $1(\mathrm{Ev})$ & - & - & - & 3 \\
\hline 3 & - & - & - & - & - & - & 1 (Avlu) & 1 \\
\hline 2 & $1(\mathrm{Ev})$ & - & - & - & - & - & - & 1 \\
\hline TOPLAM & 10 & 2 & 3 & 2 & 2 & 1 & 1 & 21 \\
\hline
\end{tabular}

Tablo 4. Tabakalara Göre Yontmataş Aletlerin Dağılımı 
Yontmataş alet yapımında daha çok dilgilerden yararlanılmış olduğu tespit edilmiştir. Diğer taraftan komşu buluntu yerlerinin yontmataş alet topluluklarına bakıldığında aletlerin yapımında daha çok yongaların tercih edilmiş olduğu görülmektedir (Gatsov, 2003; Gatsov - Nedelcheva, 2007, s.11-19; Gatsov, 2009, s.124-125; Gatsov - Nedelcheva, 2009, s.3840; Balcı, 2011, s.3). Yapılan ilk çalışmalar sonucunda yongalama işlemlerinin avlularda yapılmış olduğu tespit edilmiştir. Buna karşın aletlerin ise daha çok evlerde bulunduğu göze çarpmaktadır (Tablo 4).

Bahçelievler alet topluluğunda sayısal bakımdan ilk sırada yer alan orak elemanlarının yapımında hem dilgi hem de dilgiciklerden yararlanılmış olduğu görülmektedir (Resim 4). Söz konusu orak elemanlarının sekiz tanesi düzeltisiz, dört tanesi basit düzeltili, 1 tanesi tepesi budanmış orak elemanından meydana gelmektedir.

Bahçelievler Neolitik Çağ alet topluluğunun ok uçları keski ağızlı ok uçları ile temsil edilmektedir (Resim 5). Bu çakmaktaşı uçlardan bir tanesi 5. tabakada avludan, diğeri ise 4a tabakasında ev içinden ele geçmiştir. 5. tabakada avluda bulunan örnek 2,21 cm x 2,15 cm x $0,4 \mathrm{~cm}$; 4. tabakada ev içinden bulunan uç ise $1,69 \mathrm{~cm} \times 1,24 \mathrm{~cm}$ x 0,22 cm ölçülerindedir. Söz konusu her iki uç da dilgilerin dik ya da dike yakın düzeltilerle budanmasıyla şekillendirilmiştir.

Bahçelievler yerleşiminde söz konusu uçların yanı sıra bir ok ucu daha ele geçmiştir (Resim 6). Söz konusu uç da çakmaktaşından yapılmış olup her iki yüzden düzeltilere sahiptir ve sap kısmı bulunmaktadır. Aslında bu tipteki iki yüzden düzeltilenmiş olan uçların bölgedeki ilk örnekleri Akeramik Neolitik dönemde Keçiçayırı'nda tespit edilmiştir (Gatsov ve Nedelcheva, 2011, s. 94, Fig. 5; Efe vd. 2012, s. 230, Fig. 8).

Bahçelievler alet topluluğu içinde yer alan ön kazıyıcılardan şimdilik 3 örnek ele geçmiştir (Resim 7). Çakmaktaşından yapılan bu ön kazıyıcıların bir tanesi yonga, biri dilgi üzerine yapılmış makro ön kazıyıcı formunda iken, bir diğeri de mikro ön kazıyıcı şeklindedir. Ön kazıyıcıların işlevleri hakkındaki ortak görüş bunların deri işlemesinde kullanılmış oldukları yönündedir (Byrd, 1989, s.75; Odell, 2000, s.307). Yonganın distal kısmı üzerine yapılmış olan ön kazıyıcı 3,05 cm x 2,54 cm x 0,95 cm ölçülerindedir. Distal kısmı korunmuş olan dilgi üzerindeki ön kazıyıcı ise 2,17 cm x 1,49 x 0,33 cm ölçülerindedir. Mikro ön kazıyıcı ise tamamı korunmuş olan küçük bir yonga üzerinde yer almakta olup 1,22 cm x 1,07 cm x $0,32 \mathrm{~cm}$ boyutlarındadır. Boyutlarının küçük olmasından dolayı bu aletlerin bir sapa takılarak kullanılmış oldukları düşünülür.

Delgilerden ise 2 tane ele geçmiştir (Resim 8). Her ikisi de çakmaktaşından yapılmış olup tamamı korunmuştur. Bu delgilerden biri dilgi, diğeri de dilgicik üzerinde yer almaktadır. Taş delgiler üzerinde yapılan deneysel çalışmalar söz konusu aletlerin daha çok kuru deri, odun, kemik ya da deniz kabukları üzerinde delik açmada kullanılmış olduklarını ortaya 
koymaktadır (Yerkes, 1983; Unger-Hamilton, 1988, s.133-138; Andrefsky, 1998, s.198) .

Daha çok ahşap gibi malzemeleri tıraşlamada ya da yontmada kullanılmış olduğu düşünülen çentikli aletler ise Bahçelievler yontmataş alet topluluğunda iki örnek ile temsil edilmektedir. Bu aletlerin her ikisi de çakmaktaşı dilgi üzerine yapılmıştır. Söz konusu aletler $2,62 \mathrm{~cm} \times 1,57 \mathrm{~cm} \times 0,3 \mathrm{~cm}$ ve $3,37 \mathrm{~cm} \times 1,21 \mathrm{~cm} \times 0,52 \mathrm{~cm}$ ölçülerindedir.

Bahçelievler alet topluluğunda birer örnekle temsil edilen taş kalem ve bıçak tamamı korunmuş olan çakmaktaşı dilgicik ve dilgi üzerine yapılmıştır. Sözü edilen taş kalem 2,49 cm x 0,94 cm x 0,25 cm ölçülerinde oldukça küçük bir örnektir. Boyutları küçük olduğu için bir sapa takılarak kullanılmış olduğu düşünülmektedir.

Çakmaktaşı bıçak ise 5,93 cm x 1,47 cm x 0,2 cm ölçülerindedir. Bu boyutu ile Bahçelievler alet topluluğundaki en uzun alet grubunu oluşturmaktadır. Baskı tekniği ile çıkarılmış olan dilginin ince olmasından dolayı daha çok yumuşak malzemelerin kesiminde kullanılmış olma olasılığı bulunmaktadır. Söz konusu dilginin kesme kenarları üzerinde yoğun aşınma izleri bulunmaktadır. Diğer taraftan buluntu topluluğu içinde yer alan bazı dilgilerin de kenarlarında saptanan aşınma izlerinden dolayı bir çeşit bıçak olarak kullanılmış olduğu ileri sürülebilir. Bu durumdaki dilgilere daha çok 8. tabakada rastlanmaktadır. Ancak aletlerin işlevleri hakkında kesin bir şeyler söyleyebilmek için işlevsel analizlerin yapılması gerekmektedir.

\section{Değerlendirme ve Sonuç}

Bahçelievler Neolitik Çağ yontmataş buluntular üzerine yapılan ilk çalışmalar sonucunda yerel ve yerel olmayan olmak üzere iki hammaddenin kullanılmış olduğu sonucuna varılmıştır. Çakmaktaşının yerleşim yerinde, özellikle de avlularda yongalanmış olduğu görülür. Söz konusu avlularda yalnızca çakmaktaşının yongalanmış olduğunu gösteren çekirdek, üretim artıkları ve kabuklu örneklere rastlanmaktadır. Diğer taraftan hem çakmaktaşı hem de obsidiyen yongalamasının yapıldığı 5. tabakadaki B3-19 nolu ev dışında diğer evlerde yalnızca yontmataş aletlerin bulunmuş olması, üretimin avluda yapıldıktan sonra mekân içlerinde aletlerin kullanılmış olduğunu göstermektedir. Bunun aksine obsidiyen çekirdeklerin ve üretim artıklarının yok denilecek kadar az olmasından dolayı, obsidiyenin daha çok tamamlanmış ürünler halinde getirilmiş olduğu düşünülebilir. Benzer şekilde MÖ 6400-6300 yılları arasına tarihlenen Aktopraklık C alanı yontmataş topluluğunun \% 99'unun çakmaktaşı ve \% 1'inin obsidiyen buluntulardan meydana geldiği dikkat çeker (Balcı, 2011, s.1). Bununla birlikte yalnızca Bahçelievler'de değil, Kuzeybatı Anadolu'daki birçok çağdaş buluntu yerinde Orta Anadolu kaynaklı obsidiyen buluntuların oldukça az sayıda bulunması (Gatsov, 2009), Gatsov'un (Gatsov, 2009, s.30) da önerdiği gibi bu dönemdeki gezgin obsidiyen yontucularının varlığını düşündürtmektedir. 
Bahçelievler yerleşiminin en alt tabakasından itibaren mermi biçimli çekirdeklere rastlanmaktadır. Kuzeybatı Anadolu'da en eski mermi biçimli çekirdeklerin kullanımı Pleistocene/Holocene geçişinde, içinde Ağaçl1, Gümüşdere, Domalı gibi buluntu yerlerinin yer aldığı Ağaçlı grubu ile tanınmaktadır. Neolitik Çağ' da ise en erken örnekleri Uğurlu IV. tabaka (Erdoğu, 2013, s. 7, Fig. 46), Ulucak Höyük V. tabaka (Çilingiroğlu ve Abay, 2005, s. 12; Çilingiroğlu, 2009, s. 7, Fig.2.) ve Menteşe'de (Roodenberg, vd. 2003, s. 17-59) görülmektedir. Ayrıca Aktopraklık, Ilıpınar, Fikirtepe ve Pendik'ten de bilinmektedir (Gatsov, 2009, s. 11). Kuzeybatı Anadolu'da mermi biçimli çekirdeklerin bulunduğu kültürel tabakalar Aktopraklik C alanı (Balcı, 2011, s. 2-3) ile Menteşe'de MÖ 6400 ile Ilıpınar'da MÖ 5650 yıllarına tarihlenmektedir (Gatsov, 2009, s. 13; Roodenberg ve Thissen, 2001, s. 257-278).

Bahçelievler Neolitik Çağ tabakalarından ele geçen yontmataş buluntular içinde yer alan mermi biçimli çekirdekler, orak elemanları, ön kazıyıcılar, delgiler ve keski ağızlı uçlar, Kuzeybatı Anadolu Neolitik Çağ'ının karaktersitik yontmataş buluntularını oluşturmaktadır (Gatsov, 2009; Gatsov ve Nedelcheva, 2014, s.416; Gatsov vd. 2017, s.57-71).

Kuzeybatı Anadolu'da MÖ 7000-6000 yılları arasında görülen keski ağızlı uçlara (Gatsov ve Nedelcheva, 2011, s. 91), Akdeniz Bölgesi'nde sıklıkla görülmektedir (Taşkıran, 2013, s. 4). Antalya'da Öküzini Mağarası'nın Geç Neolitik-İlk Kalkolitik dönem tabakasında (Kartal, 2002, s. 240); Beldibi Kayaaltı Sığınağı'nın Geç Epipaleolitik-Erken Neolitik tabakasında (Bostanc1, 1959, s. 140; Plate V/7), Karain Mağarası'nın Geç Neolitik, Kalkolitik ve Erken Tunç Çağı tabakalarında (Yalçınkaya vd. 2000, s. 17; Yalçınkaya vd. 2011, s. 28), Suluin Mağarasının Orta Kalkolitik tabakalarında rastlanmaktadır (Taşkıran ve Aksu, 2009, s.94; Taşkıran ve Aksu, 2011, s.39-40; Taşkıran vd. 2011, s.431).

Bahçelievler yerleşiminde mermi biçimli çekirdekler ile keski ağızlı uçların varlığı ve baskı tekniğinin kullanımı Kuzeybatı Anadolu'da yaşayan toplumların MÖ. 7. binyılda benzer teknolojik becerilere sahip olduklarını ve benzer alet geleneğini paylaşmış olduklarını ortaya koymaktadır. Diğer taraftan, Kuzeybatı Anadolu'da görülen yoğun yonga üretimine dair izlere Bahçelievler'de rastlanılmamaktadır. Bahçelievler yerleşiminde yongaların yalnızca ön kazıcıyıcıların yapımında, dilgilerin ise orak elemanları ve delgilerin üretiminde kullanılmış olması Kuzeybatı Anadolu'da Ilıpınar, Fikirtepe ve Aktopraklık Neolitik Çağ yontmataş toplulukları (Gatsov, 2003) ile benzerlik gösterir.

Yontmataş alet topluluğunda orak elemanlarının diğer alet tiplerine oranla daha fazla sayıda bulunmuş olması dikkat çekicidir. Korobkova'nın (Korobkova, 1996; Korobkova, 1999) orak elemanları üzerine yaptığı deneysel çalışmalar, orak elemanlarının lateral kenarları üzerinde yer alan silika parlaklığı genişliğinin 0,1-0,3 cm arasında olması bu aletlerin tarım aktivitesinde değil de diğer bitkilerin kesiminde kullanılmış olduğunu göstermiştir. Bahçelievler'den ele geçen söz konusu aletlerin yanal kenarları üzerindeki silika parlaklığı 
genişliğinin 0,3-0,58 $\mathrm{cm}$ arasında olması bunların tarım aktivitesinde kullanılmış olduğunu ortaya koymaktadır. Kısacası Bahçelievler insanları bu aletleri bir sapa yan yana takarak bir kompozit alet olarak tahıl başaklarını kesmek için kullanılmış olmalılardır. Bu durum, Bahçelievler yerleşiminde tarımın önemli bir yere sahip olduğunu ortaya koymaktadır. Bir doktora tezi kapsamında çalışılan yerleşmenin ilk arkeobotanik sonuçları da tarıma alınan ürün çeşitliliği bakımından bu fikri doğrulamaktadır.

Bahçelievler Neolitik Çağ yontmataş topluluğunun gerek hammadde kullanımı gerekse tekno-tipolojik özellikleri bakımından daha çok Menteşe ve Barcın topluluğu ile benzerlik gösterdiği tespit edilmiştir. Dilgi ve dilgicik üretiminin yonga üretiminden fazla olması, alet yapımında daha çok dilgilerden yararlanılması ve alet tipleri olarak yonga ön kazıcıyılar ile düzeltili dilgi aletlerin bulunması bu görüşü güçlendirmektedir.

Sonuç olarak, Bilecik Bahçelievler Neolitik Çağ yontmataş topluluğu üzerine yapılan bu ilk çalışma, yerleşmenin genel karakteri itibariyle Kuzeybatı Anadolu buluntu yerleri ile büyük bir benzerlik gösterdiğini ortaya koymaktadır. Ağırlıklı olarak çakmaktaşı kullanımı, dilgi ve dilgicik üretiminde kullanılan konik ve mermi biçimli çekirdekler ile keski ağızlı uç, delgi ve ön kazıyıcı üretimi bu görüşü destekleyen güçlü kanıtları oluşturmaktadır. Aynı bölgede yer alan çağdaş yerleşim yerlerinin yontmataş toplulukları arasındaki bu benzerliklerin niteliği, diğer malzeme grupları incelendikten sonra çok daha iyi anlaşılacaktır.

\footnotetext{
Hakem Değerlendirmesi: Dış bağımsız.

Çıkar Çatışması: Yazar çıkar çatışması bildirmemiştir.

Finansal Destek: Yazar bu çalışma için finansal destek almadığını beyan etmiștir.

Peer-review: Externally peer-reviewed.

Conflict of Interest: The author has no conflict of interest to declare.

Grant Support: The author declared that this study has received no financial support.
}

\section{Kaynakça/References}

Andrefsky, W. (1998). Lithics: Macroscopic Approaches to Analysis. Cambridge: Cambridge University Press.

Balc1, S. (2011). The Chipped Stone Industry of Aktopraklık C (Bursa): Preliminary Results. Anatolia Antiqua, (XIX), 1-11.

Bostanc1, E. Y. (1959). Researches on the Mediterranean Coast of Anatolia a New Palaeolithic Site at Beldibi Near Antalya. Anadolu/Anatolia, (4), 129-178.

Byrd, B. (1989). The Natufian Encampment at Beidha, Late Pleistocene Adaptation in Southern Levant. Aarhus: Aarhus University Press.

Carter, T. ve Milić, M. (2013). The Consumption of Obsidian at Neolithic Çatalhöyük: A Long-Term Perspective. in F. Borrell, J.J. Ibanez and M. Molist (Eds.), Stone Tools in Transition: From HunterGatherers to Farming Societies in the Neat East. 7th Conference on PPN Chipped and Ground Stone 
Industries of the Fertile Crescent (pp. 495-508). Barcelona,: Servei de Publications.

Carter, T. ve Shackley, M.S. (2007). Sourcing obsidian from Neolithic Çatalhöyük (Turkey) using Energy Dispersive X-ray Fluorescence. Archaeometry, 49(3), 437-454.

Carter, T., Poupeau, G., Bressy, C. ve Pearce, N.J.G. (2006). A New Programme of Obsidian Characterization at Çatalhöyük, Journal of Archaeological Science, (33), 893-909.

Conolly, J. (1999). The Çatalhöyük Flint and Obsidian Industry. Technology and Typology in Context. Oxford: Archaeopress.

Çilingiroğlu, A. ve Abay E. (2005). Ulucak Höyük Excavations: New Results. Mediterranean Archaeology and Archaeometry, 5(3), 5-21.

Çilingiroğlu, Ç. (2009). Of Stamps, Loom Weights and Spindle Whorls: Contextual Evidence on the Function(s) of Neolithic Stamps from Ulucak, Izmir, Turkey. Journal of Mediterranean Archaeology, 22(1), 3-27.

Efe, T., Gatsov, I. ve Nedelcheva, P. (2012), Keçiçayırı. A Neolithic Settlement near Seyitgazi, Eskişehir. in M. Özdoğan, N. Başgelen, P. Kuniholm (Eds.), The Neolithic in Turkey. New Excations \& New Research. Western Turkey (pp. 227-236). İstanbul: Arkeoloji ve Sanat Yayınları.

Efe, T., Türkteki, M., Sarı, D. ve Fidan, E. (2015). Bilecik İli 2013 Yılı Yüzey Araştırması. 32. Araştırma Sonuçları Toplantısı, (1), 495-504.

Erdoğu, B. (2013). Uğurlu. A Neolithic Settlement on the Aegean Island of Gökçeada. in M. Özdoğan, N. Başgelen and P. Kuniholdm (Eds.), The Neolithic in Turkey. New Excavations\& New Research. Northwestern Turkey and İstanbul (pp. 1-33). İstanbul: Arkeoloji ve Sanat Yayınlar1.

Fidan, E. (2020). Fikirtepe Kültürü ve Öncesi: Bilecik Bahçelievler Kurtarma Kazısı'nın İlk Sonuçları. Arkeoloji ve Sanat Dergisi, (163), 29-38.

Gatsov, I. (2003). The Latest Results from the Technological and Typological Analysis of Chipped Stone Assemblages from Ilıpınar, Pendik, Fikirtepe and Menteşe, NW Turkey. Documenta Praehistorica, (XXX), 153-158.

Gatsov, I. (2009) Prehistoric Chipped Stone Assemblages from Eastern Thrace and the South Marmara Region 7th-5th mill. B.C. BAR International Series, (1904), 1-135.

Gatsov, I. ve Nedelcheva, P. (2007). Chipped Stone Assemblages of Menteşe and the Problem of the Earliest Occupation of Marmara Region. in Kozlowski, Nowak (Eds.), Mesolithic/Neolithic Interactions in the Balkans and in the Middle Danube Basin(pp. 7-20). Oxford: British Archaeological Reports.

Gatsov, I. ve Nedelcheva, P. (2009). Chipped Stone Artifacts from Barcın Höyük, Bibliotheca Historica et Archaeologica Banatica XLIX, Ten Years After: The Neolithic of the Balkans, as Uncovered by the Last Decade of Research, 37-48.

Gatsov I. ve Nedelcheva P. (2011). Neolithic Chipped Stone Assemblages in North Western Anatolia, Turkey. Eurasian Prehistory, 8(1-2), 89-95.

Gatsov, I. ve Nedelcheva, P. (2014). Lithic Production Before and After the 4th Millennium BC on the Lower Danube, in Southeast Bulgaria, the Marmara Region and the Eastern Aegean. in B. Horejs, M. Mehofer (Eds.), Western Anatolia before Troy. Proto-Urbanisation in the 4th Millennium BC? (pp. 413-419). Vienna: Austrian Academy of Sciences Press.

Gatsov, I. ve P. Nedelcheva (2018). Bullet core pendatns from South Marmara region. in P. Valde-Nowak, K. Sobczyk, M. Nowak ve J. Zealka (Eds.), Multar per Gentes et Multa per Saecula. Amici Mağıstro et 
Collegae suo Ioanni Christopho Kozlowski Dedicant (pp. 301-305). Krakow: Alter Publishing House.

Gatsov, I., Kay, M. ve Nedelcheva, P., (2012). Lithic Assemblages from the Prehistoric Settlement at Barcın Höyük, Northwestern Anatolia. New Results. Eurasian Prehistory 9(1-2), 125-133.

Gatsov, I., Nedelcheva, P., Kaczanowska M., Kozlowski, J. K. (2017). Lithic industries and their role in Neolithisation models in Southeast Europe, in A. Reingruber, Z. Tsirtsoni, P. Nedelcheva (Eds), Going West? The Dissemination of Neolithic Innovations between the Bosporus and the Carpathians. Proceedings of the EAA Conference (57-71). London: Cambridge University Press.

Gerritsen, F. (2010). Barcın Höyük Excavations, 2008. 29. Kazı Sonuçları Toplantısı, 411-420.

Kartal, M. (2002). The Microliths of Öküzini Cave. in I. Yalçınkaya - M. Otte - J. Kozlowski - O. Bar-Yosef (Eds), La Grotte d'Öküzini: Evolution du Paléolithique final du sudouest de l'Anatolie - Öküzini: Final Paleolithic evolution in southwest Anatolia (pp. 235-252), Liège: Université de Liège.

Kayacan, N. ve Altınbilek-Algül, Ç. (2018). Aşıklı Höyük Obsidian Studies: Production, Use and Diachronic Changes. in M. Özbaşaran, G. Duru ve M. Stiner (Eds.), The Early Settlement at Aşıklı Höyük. Essays in Honor of Ufuk Esin (pp. 363-382), İstanbul: Ege Yayınları.

Korobkova, G. (1996) The Blades with "Mirror-like" polishing: Myth or reality. in S.K. Kozlowski ve H. G. K. Gebel (Eds.), Neolithic Chipped Stone Industries of the Fertile Crescent, and Their Contemporaries in Adjacent Regions. Proceedings of the second workshop on PPN Chipped Lithic Indusries (pp. 227-232), Berlin: Institute of Archaeology.

Korobkova, G. (1999). The blade with "Mirror-like polishing": The myth or the reality. in Kozlowski, S. (Eds.), The Eastern Wing of the Fertile Crescent: Late Prehistory of Greater Mesopotamian Lithic Industries (pp. 18-20), Oxford: Archaepress.

Odell, G.H. (2000). Stone Tool Research at the End of the Millenium Procurement and Technology Journal of Archaeological Research 8 (4): 269-331.

Roodenberg, J. ve Thissen, L. (Ed.). (2001). The Ilıpınar Excavations II. Leiden-Istanbul: PIHANS.

Roodenberg, J., Jacobs, A. van As, L. ve Wijnen, M.-H. (2003). Early settlement in the plain of Yenişehir (NW Anatolia). The basal occupation layers at Menteşe. Anatolica, (29),17-59.

Taşkıran, H. ve Aksu, S. E., (2009). Suluin Mağarası 2007 Yılı Kazısı. 30. Kazı Sonuçları Toplantısı, (2), 89-100.

Taşkıran, H. ve Aksu, S.E. (2011) Suluin Mağarası Kazısı 2008. 32. Kazı Sonuçları Toplantısı, (3), 36-45.

Taşkıran, H., Aksu, S.E., Kösem, M.B. ve Özçelik, K.. (2011). Suluin Mağarası Kazısı 2009. 32. Kazı Sonuçları Toplantısı, (4), 427-439.

Taşkıran, Z. (2013). Keski Ağızlı/Yatay Ok Uçları. Anadolu/Anatolia, ( 39), 1-12.

Unger-Hamilton, R. (1988). Method in Microwear Analysis, Prehistoric Sickles and Other Stone Tools from Arjoune, Syria. Oxford: BAR Publishing.

Yalçınkaya, I., Otte, M., Taşkıran H., Özçelik K., Atıcı, A. L., Kösem, M. B.,. Erek, C. M ve Kartal M. (2000). 1998 Yılı Karain Kazısı. 21. Kazı Sonuçları Toplantısı, (1), 15-28.

Yalçınkaya, I., Taşkıran, H., Özçelik, K.ve Kösem, M. B. (2011). 2009 Yılı Karain Mağarası Kazıları. 32. Kazı Sonuçları Toplantısı, (3), 22-35.

Yerkes, R.W. (1983). Microwear, Microdrills and Missipian Craft Specialization. American Antiquity, (48), 499-518 


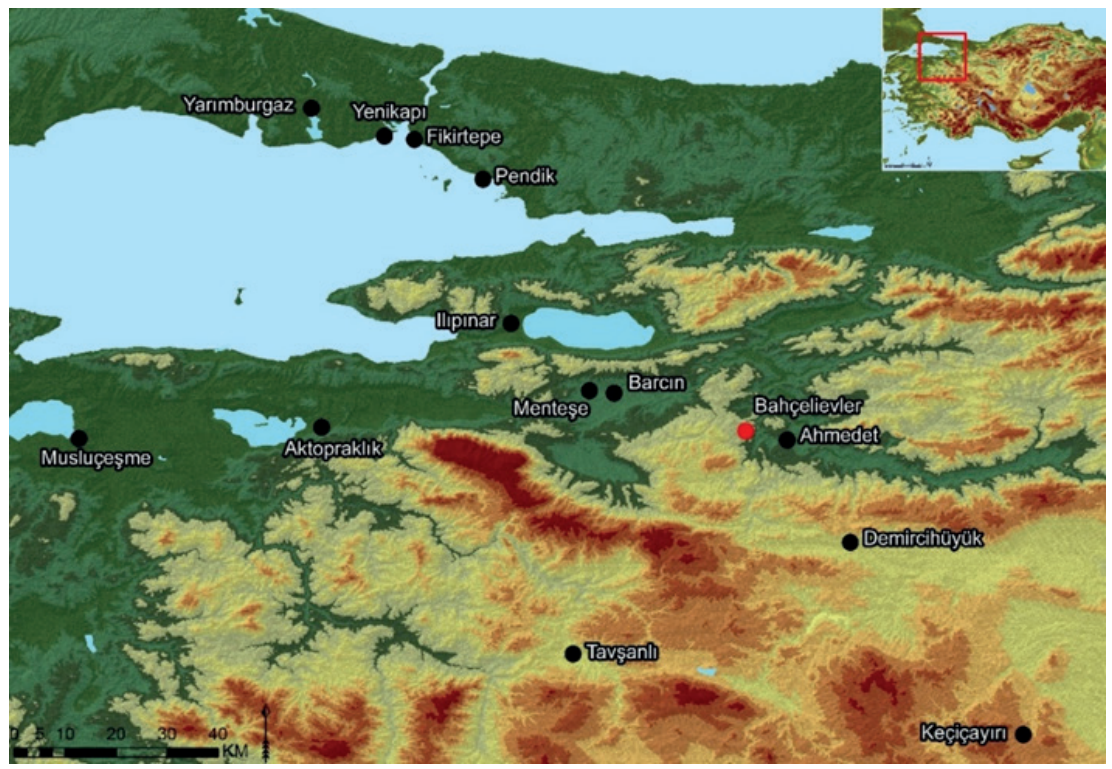

Harita 1. Kuzeybatı Anadolu'da Neolitik Çağ Yerleşmeleri

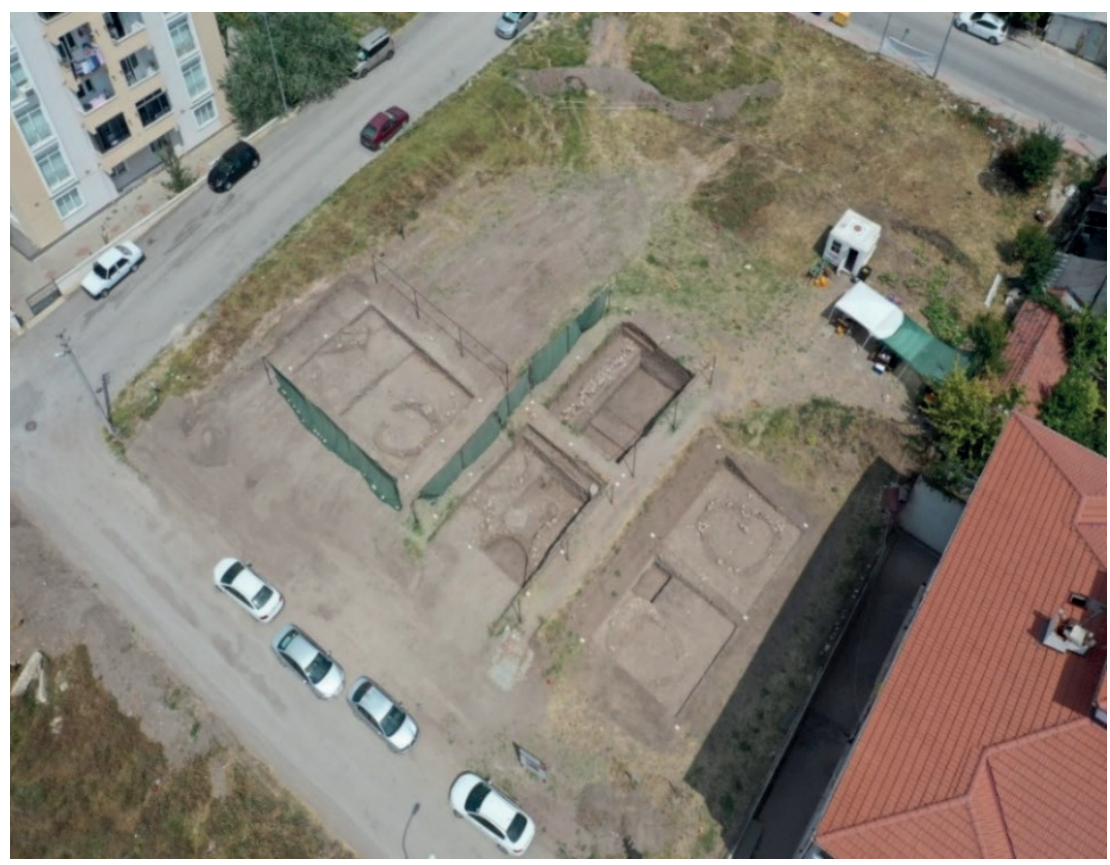

Resim 1. 2020 yılı kazıları sonunda Bahçelievler Yerleşmesi Hava Fotoğrafı 


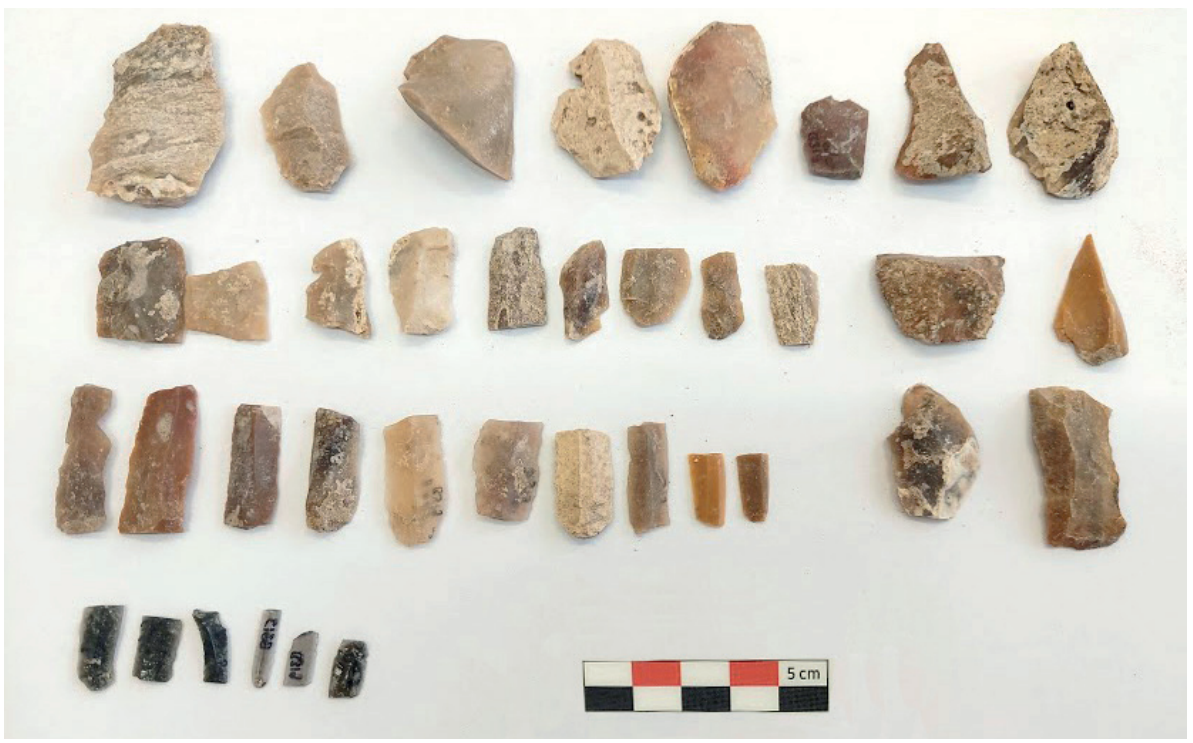

Resim 2. B3-19 Nolu Ev (5.tabaka) İçinden Ele Geçen Çakmaktaşı ve Obsidiyen Buluntular 

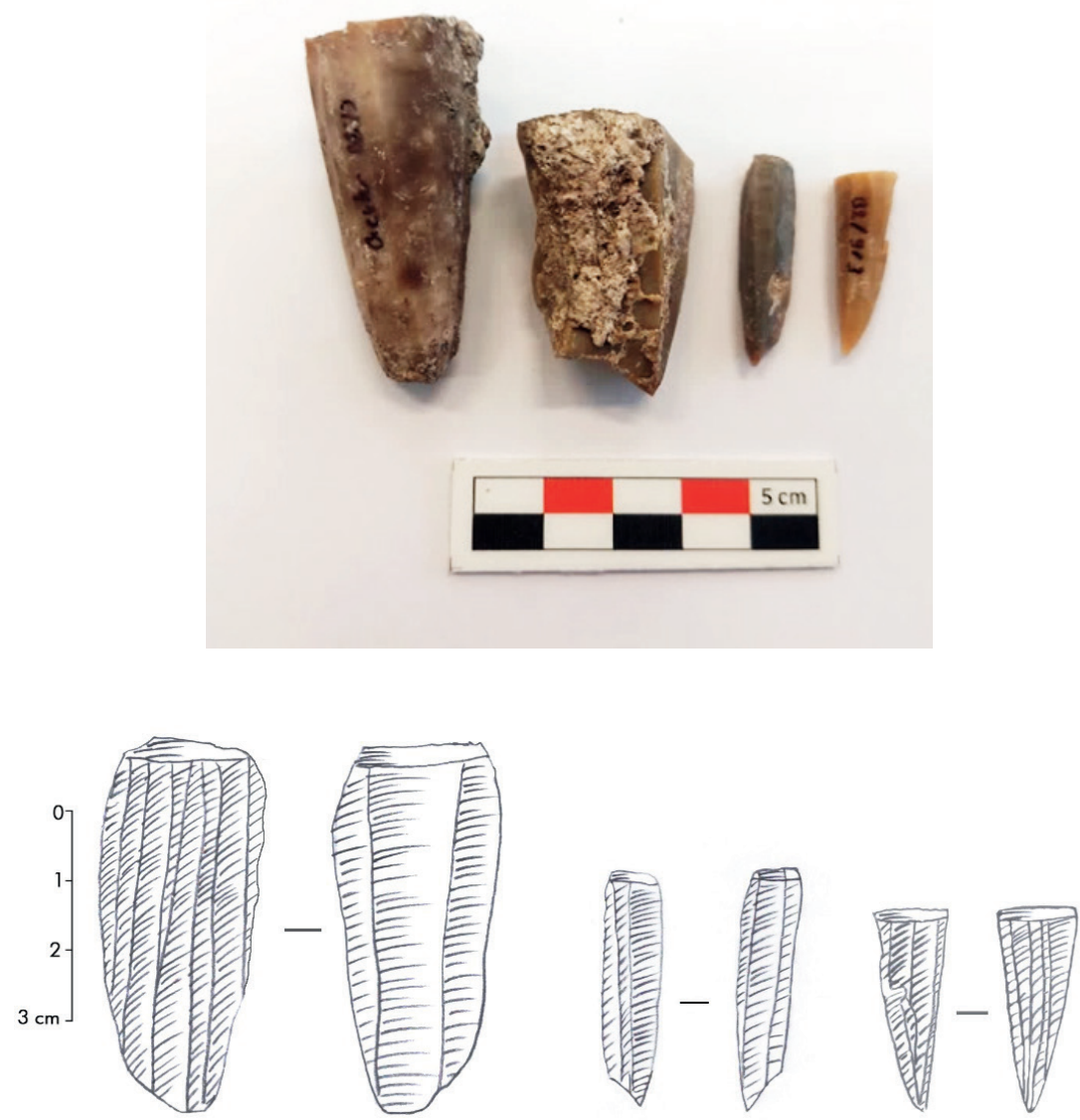

Resim 3. Çakmaktaşı Konik ve Mermi Biçimli Çekirdekler 

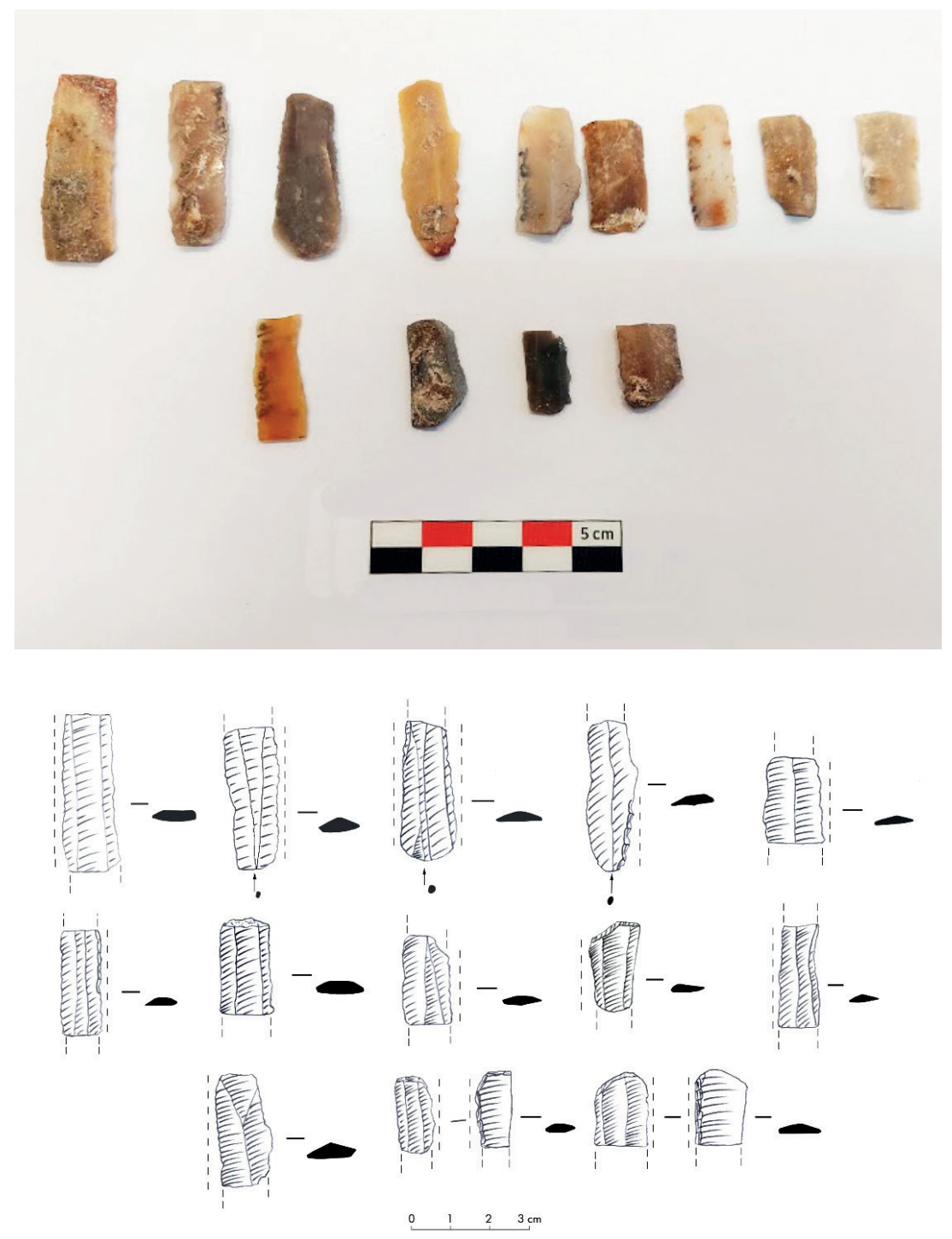

Resim 4. Çakmaktaş1 Orak Dilgi ve Dilgicikleri 

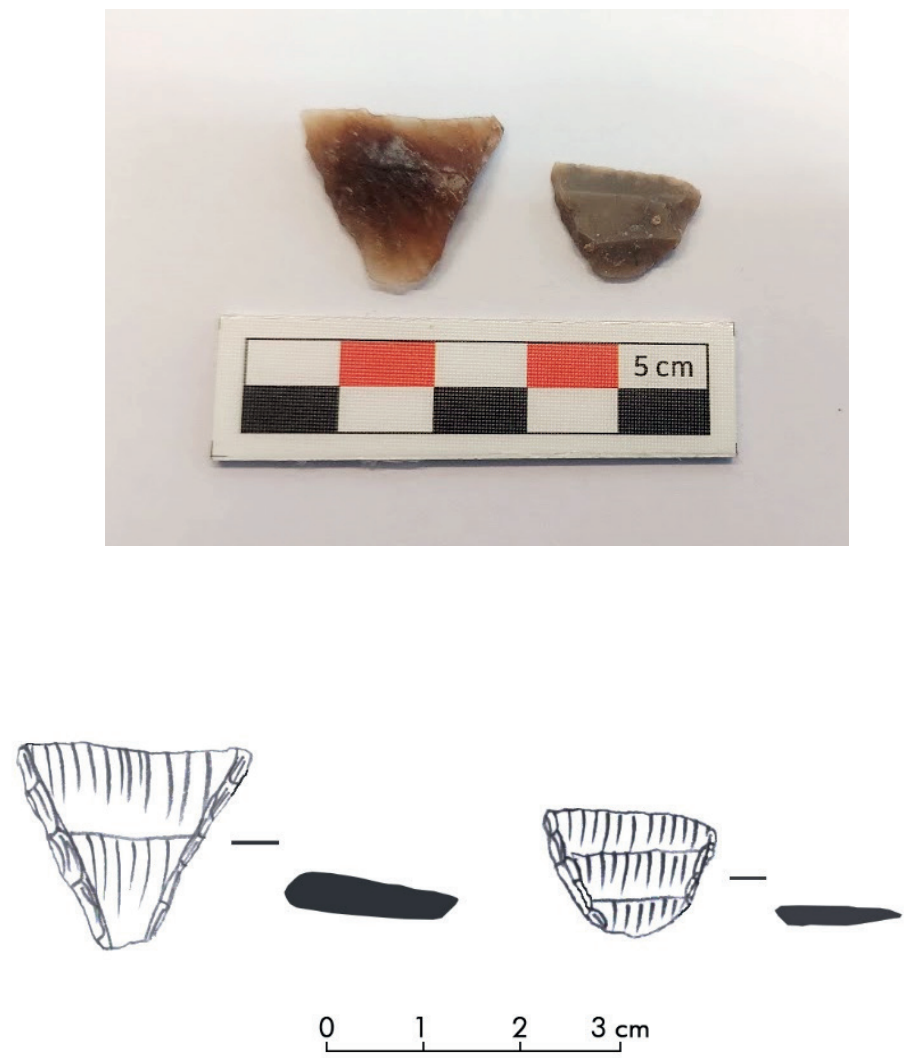

Resim 5. Çakmaktaşı Keski Ağızlı Ok Uçları 


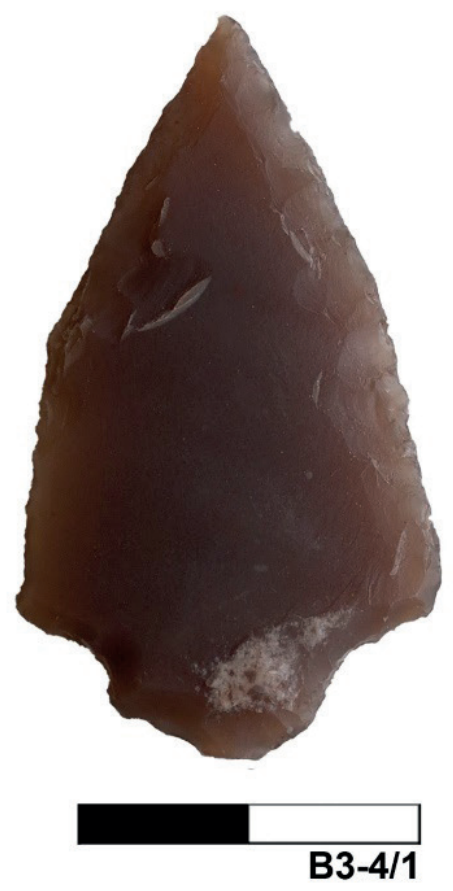

Resim 6. Çakmaktaşı Düzeltili Ok Ucu 

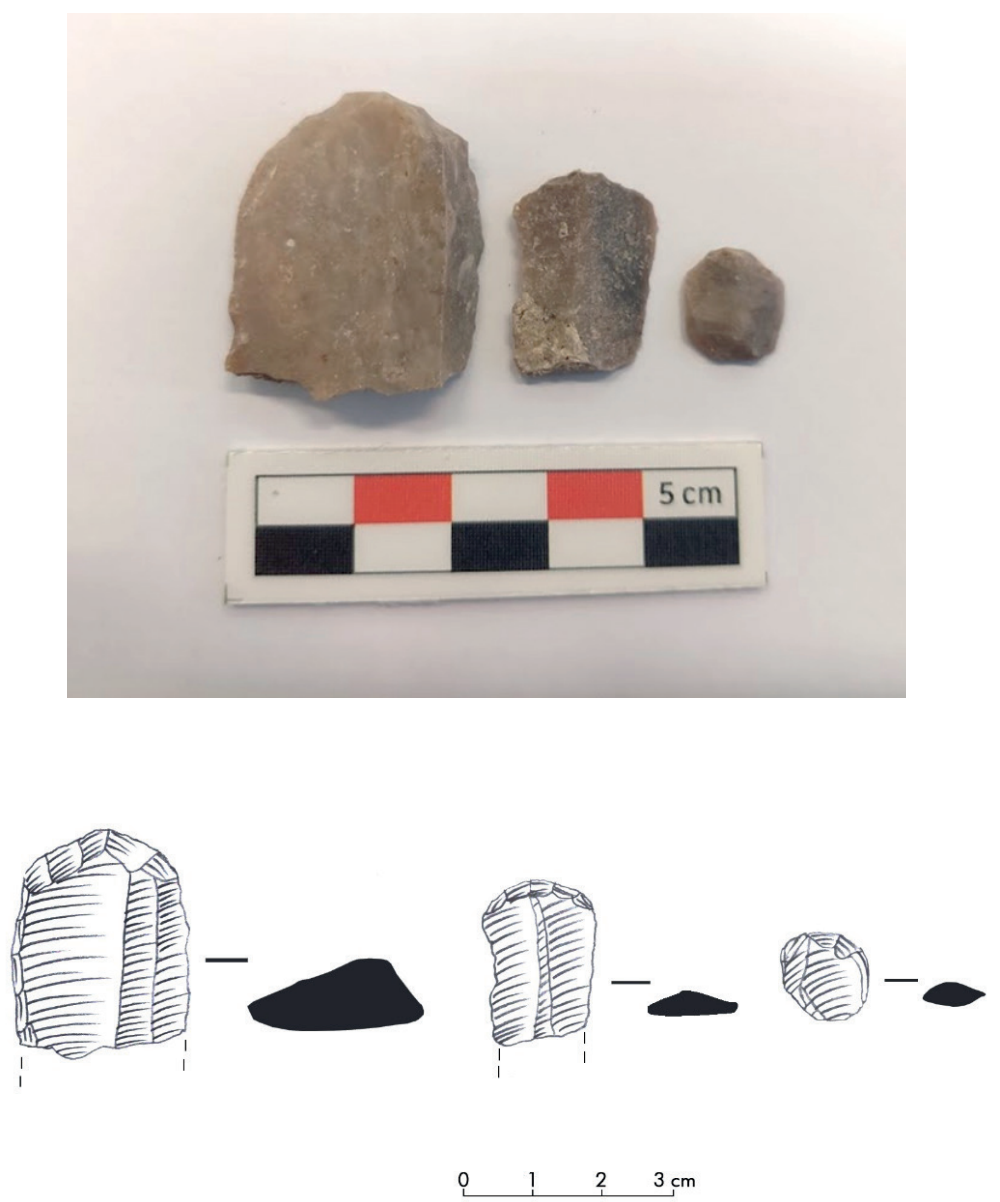

Resim 7. Çakmaktaşı Ön Kazıyıcılar 

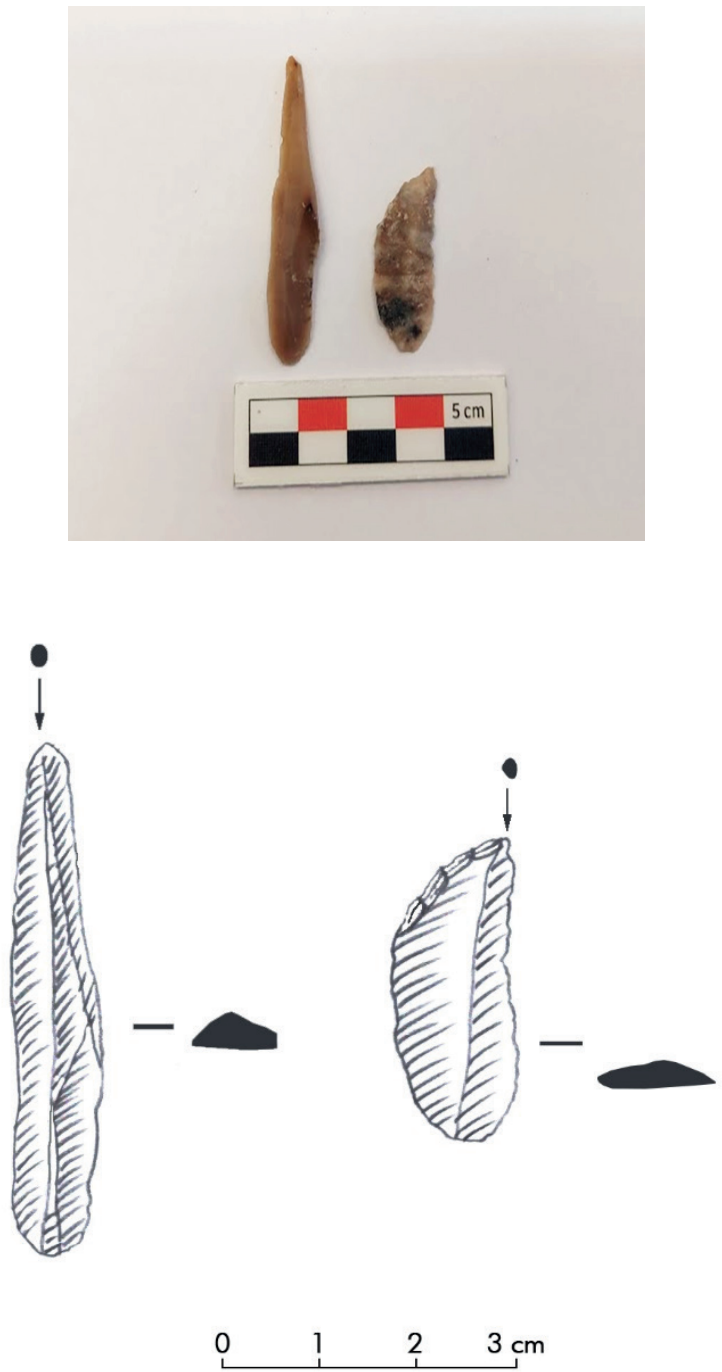

Resim 8. Çakmaktaşı Delgiler 